\title{
Does Usability Matter? An Analysis of the Impact of Usability on Technology Acceptance in ERP Settings
}

\author{
Brenda Scholtz \\ Nelson Mandela \\ Metropolitan University, \\ Port Elizabeth, South Africa
}

brenda.scholtz@nmmu.ac.za

\author{
Imran Mahmud \\ Daffodil International University, \\ Dhaka, Bangladesh \& \\ Universiti Sains Malaysia, \\ Penang, Malaysia
} imranmahmud@daffodilvarsity.edu.bd

\section{T. Ramayah \\ Universiti Sains Malaysia, Penang, \& Universiti Teknologi Malaysia International Business School (UTM-IBS), Kuala Lumpur, Malaysia \\ ramayah@usm.my}

\begin{abstract}
Though the field of management information systems, as a sector and a discipline, is the inventor of many guidelines and models, it appears to be a slow runner on practical implications of interface usability. This usability can influence end users' attitude and behavior to use IT. The purpose of this paper was to examine the interface usability of a popular Enterprise Resource Planning (ERP) software system, SAP, and to identify related issues and implications to the Technology Acceptance Model (TAM). A survey was conducted of 112 SAP ERP users from an organization in the heavy metal industry in Bangladesh. The partial least squares technique was used to analyze the survey data. The survey findings empirically confirmed that interface usability has a significant impact on users' perceptions of usefulness and ease of use which ultimately affects attitudes and intention to use the ERP software. The research model extends the TAM by incorporating three criteria of interface usability. It is the first known study to investigate usability criteria as an extension of TAM.
\end{abstract}

Keywords: Enterprise Resource Planning, Interface usability, ERP usability, Technology Ac-

(CC BY-NC 4.0) This article is licensed to you under a Creative Commons AttributionNonCommercial 4.0 International License. When you copy and redistribute this paper in full or in part, you need to provide proper attribution to it to ensure that others can later locate this work (and to ensure that others do not accuse you of plagiarism). You may (and we encourage you to) adapt, remix, transform, and build upon the material for any non-commercial purposes. This license does not permit you to use this material for commercial purposes. ceptance Model, Partial Least Squares

\section{Introduction}

In our global, connected economy sophisticated software systems are increasingly made available to management in enterprises for measuring, analyzing, improving, and controlling business activities and overall performance. These enterprise systems can assist organizations to process huge amounts of 
information effectively within complex and usually distributed working environments, against an enormous variety of tasks (from gathering business intelligence to managing safety-critical systems). Enterprise Resource Planning (ERP) systems are claimed to integrate, improve, support, and complete management solutions by transacting and incorporating potentially all business functions of an enterprise (Vaman, 2007). An ERP system can be defined as a software package that permits seamless integration of all company information, including information pertaining to several business units in an organization, such as finance, accounting, manufacturing, and human resources. An ERP system is designed to integrate all functions and departments across an entire enterprise and still serve the needs of each individual department (Forcht, Kieschnick, Aldridge \& Shorter, 2007).

The primary benefit of ERP systems relates to the integration of data and processes and improved business efficiency (Huang, Huang, Wu \& Lin, 2009). Another benefit of these integrated systems is their focus on customers, improvement in process efficiency, and support for building teams of employees that cross functional areas (Motiwalla \& Thompson, 2012). As a result of the potential benefits reaped by ERP systems, they have been adopted by the majority of enterprises globally (Zouine \& Fenies, 2014). According to a recent Gartner Forecast Analysis report (Eid \& Granetto, 2014), worldwide the ERP software market is predicted to grow from $\$ 25.4 \mathrm{~B}$ in 2013 to $\$ 35.2 \mathrm{~B}$ in 2018. SAP AG is the leading ERP system and in 2013 retained their market leadership position and sold \$6.1B in ERP software, a slight increase from $\$ 6 \mathrm{~B}$ in 2012 (Great Speculations, 2014). Oracle was second in sales in 2013 with $\$ 3.117 \mathrm{~B}$ and in third place was Sage with $\$ 1.5 B$.

In spite of the potential benefits of ERP systems and the growing ERP market, ERP system project failure rates are still high (Kimberling, 2012; Panorama Consulting Solutions, 2014). It is predicted that ERP failure rates will not slow down in the near future (Kimberling, 2012). The 2014 ERP Panorama Report revealed that 54 percent of projects exceeded projected budgets and 72 percent exceeded planning durations, with 66 percent receiving only 50 percent of the measurable anticipated benefits (Panorama Consulting Solutions, 2014).

ERP systems are known for being profoundly complex and having poor usability (Faisal, Faridi, Javed \& Shahid, 2012; Lambeck, Fohrholz, Leyh, Šūpulniece \& Müller, 2014; Oja \& Lucas, 2011; Šūpulniece, Boguševiča, Petrakova, \& Grabis, 2013; Veneziano, Mahmud, Khatun \& WaiPeng, 2014). Small improvements in usability of an ERP system have been shown to produce many benefits to an organization, and the greater the ease of use of the system, the greater the probability of implementation success (Ceaparu, Lazar, Bessiere, Robinson \& Shneiderman, 2004; Almajali, Masa'deh \& Tarhini, 2016). Conversely, the Faisal et al. (2012) study revealed that a poorly arranged user interface can negatively affect user performance and efficiency. The poor usability of ERP systems has been reported to cause failures and inefficiencies on process management, which can generate frustration to users or resistance (Hawari \& Heeks, 2010; Lambeck et al., 2014; Singh \& Wesson, 2009; Yeh, 2006). These users might need longer time to learn how to interact with an ERP system than planned, and they are often faced with a number of difficulties while using it (Lambeck et al., 2014; Topi, Lucas \& Babaian, 2005; Wai-Peng, Veneziano, \& Mahmud, 2015).

The concept of interface usability is related to Human Computer Interaction (HCI) issues and can be decomposed into a number of different attributes or qualities (Albert \& Tullis, 2013). When applied to software engineering, usability provides specific approaches from the field of design, as in user-centered design, to the field of testing, as in Heuristics Evaluations. These approaches should guide the development of "easy to use" or "user-friendly" systems, mostly by leveraging how their features are perceived (and cognitively processed) by its users. Ease of use and user acceptance of a system have both been shown to be an important factor in the success of a newly adopted ERP system (Almajali et al., 2016; Al-Jabri \& Roztocki, 2014; Hawari \& Heeks, 2010; Soto-Acosta, Ramayah \& Popa, 2013). 
Usability analysis of Information Technology (IT) and Information Systems (IS) continues to be an expensive and often neglected practice in organizations in developing countries (Grigera, Garrido, Rivero, \& Rossi, 2017). Additional research studies are required to determine if the problems in ERP projects are caused by usability problems (Šūpulniece et al., 2013). The high rate of implementation project failure emphasizes the need for research on the usability and acceptance of ERP systems. In this paper, it is argued that the interface usability of the SAP ERP system has not been fully tested and enhanced by its software developers and suppliers, and that there is scope, need, and urgency to revise the way we look at usability, at least in terms of the use of the SAP ERP system. The Technology Acceptance Model (TAM) theory has been applied in several studies of ERP systems (Agrifoglio \& Metallo, 2010; Bueno \& Salmeron, 2008; Escobar-

Rodríguez \& Bartual-Sopena, 2014); however, few studies have explored the impact of usability issues on the TAM.

The purpose of this study was to investigate the interface usability (also referred to as usability) and acceptance of ERP systems, particularly the impact of usability on end users' attitude and behavior. In order to achieve this objective, a survey was conducted of users in a medium sized metal company located in Bangladesh. The users were asked to evaluate the usability of SAP ERP and their acceptance of the system. Acceptance of the system was measured by four criteria as proposed by the TAM theory (F. D. Davis, Bagozzi, \& Warshaw, 1989), namely: Perceived Usefulness (PU), Perceived Ease of Use (PEOU), Attitude Towards Usage (ATU), and Behavioral Intention to Use (BIU) the SAP ERP system. The statistical analysis technique of Structural Equation Modelling (SEM) was used to test the relationship among the variables of the proposed research model.

The results from this research can contribute to our knowledge about the attitude and behavior of users towards ERP systems in the manufacturing sector in Bangladesh or in similar economies. In addition, this research can provide some deeper insights into the overall ERP usability domain as well as into improving the usability of other IS applications. This research extends the TAM model to include three usability criteria, namely: navigation, learnability, and presentation.

The structure of the paper is as follows. First, it discusses the research problems, followed by a literature review on the background of the TAM theory and a discussion of its relevance to ERP research, methods of measuring the usability of an ERP system, and proposed research model. Then, it documents the research methodology of this study and data analysis. Next, it reports results and discusses research findings. Finally, the paper concludes with discussion of the limitations of the study, future research directions, and implications of the findings for practice.

\section{Related Research}

\section{ERP Systems}

ERP systems have long been criticized regarding their complexity. This complexity is due to the integration of different business applications and the processing of huge amounts of data. Furthermore, the functionality and complexity of systems create confusion and frustration (Hawari \& Heeks, 2010; Matthews, 2008; Ramayah \& Lo, 2007; Veneziano et al. 2014, Wai-Peng et al. 2015), which results in negative responses from users and mistakes made while working on such applications (Al-Jabri \& Roztocki, 2014; Kwak, Park, Chung, \& Ghosh., 2012). Almahamid \& Awsi (2015) explained the importance of ERP vendor support and an organizational environment for the users' perceived benefit of ERP. Some studies (Lambeck et al., 2014; Veneziano et al., 2014; Wai-Peng et al., 2015) argue that the complexity of ERP systems stem mainly from the "unfriendly" nature of the user interface with its multiple windows and high level of detail, whilst 
others (Ceaparu et al., 2004; Matthews, 2008; Veneziano et al., 2014) argue that complex ERP systems end up providing less effective functionality if they have usability problems.

Literature reports that many ERP projects have struggled to achieve expected and significant benefits due to problems with the complexity of their user interface and poor usability (Ceaparu et al., 2004; Singh \& Wesson, 2009; Wai-Peng et al., 2015) and with learning how to use the ERP system effectively (C. H. Davis \& Comeau, 2004). The complex functions and interface of ERP systems can also cause users to lack interest in these systems (Gumussoy, Calisir, \& Bayram, 2007). Low levels of usability and end-user acceptance can contribute to the failure of an ERP system implementation (Al-Jabri \& Roztocki, 2014; Hawari \& Heeks, 2010; Soto-Acosta et al., 2013).

In Bangladesh, ERP system implementation has increased in medium-sized organizations by almost $11 \%$ and for large-sized organizations, up to $26 \%$ in the last couple of years (Business Wire, 2011). In the last few years in Bangladesh, the SAP ERP system has become very popular in the manufacturing and telecom industries, with almost 50 local and foreign companies currently using SAP (Imran, 2013). Despite having focused on the need for technology development in Bangladesh, slow internet rates and a lack of proper training has led to ERP systems not meeting acceptable conditions (Mukaddes, Chowdhury, \& Uddin., 2010). Problems with ERP implementations in Bangladesh have been reported as due to a lack of communication, structured training, and poor usability (Veneziano et al., 2014; Wai-Peng et al., 2015).

\section{Technology Acceptance Model (TAM) in ERP Research}

Despite several investigations of the relationship between TAM and ERP systems in various studies, little is known about the impact of user interface quality on the acceptance of these systems. A richer understanding of the user interface issues encountered and factors influencing users' perceptions, attitude, and behavior can assist software designers, developers, and testers of ERP software with focusing on those factors to increase the intention to use an ERP system.

The TAM theory originally proposed by F. D. Davis et al. (1989) has been used in various versions in several studies (Agrifoglio \& Metallo, 2010; Bueno \& Salmeron, 2008; Hwang, 2005; Sternad \& Bobek, 2013) to investigate ERP system adoption and acceptance for end users. The TAM proposes that a higher level of perceived usefulness (PU) and perceived ease of use (PEOU) will lead to a higher level of positive attitude towards usage (ATU) of that system, which finally indicates a higher degree of behavioral intention to use (BIU) the system. F. D. Davis et al. (1989) defines PU as the extent to which a person believes that the use of a particular system will improve his/her work performance. PEOU is a construct expressing the extent to which the respondent believes that the use of the concrete system is simple for him/her or it will not be hard. ATU (or attitude) can be defined as the user's positive or negative feelings about performing the target behavior (Fishbein \& Ajzen, 1975, p. 288). BIU, also known as behavioral intention or BI, is a measure of the strength of one's intention to perform a specified behavior.

Our review of literature shows that there are a number of studies using TAM to measure the attitude and behavior of end users (Amoako-Gyampah, 2007; Garača, 2011; Gumussoy et al., 2007; Shih \& Huang, 2009). Various researchers detected the links between PU and PEOU (Agrifoglio \& Metallo, 2010; Calisir \& Calisir, 2004; Escobar-Rodríguez \& Bartual-Sopena, 2014), though some researchers also ignored this relation (Ali \& Younes, 2013; Al-Jabri \& Roztocki, 2014; Garača, 2011). The reliability of the TAM questionnaire was tested by Hendrickson, Massey, and Cronan (1993) and its validity was investigated by Szajna (1996).

Several variables have been proposed within TAM to influence users' technology acceptance behavior towards ERP systems (Table 1). Some of these studies focused on the internal managerial practices such as training (Amoako-Gyampah \& Salam, 2004; Lee, Lee, Olson, \& Chung, 2010) 
and management support (Shih \& Huang, 2009), whilst another study (Calisir \& Calisir, 2004) focused on system capability and learnability and yet others incorporated cognitive (enjoyment) factors into the TAM (Hwang, 2005; Mayeh, Ramayah, \& Popa, 2014). Venkatesh and Davis (1996) identified self-efficacy (SE) as an antecedent of PEOU. After that, SE became a very popular construct that was added to the TAM model various times for ERP research. It has been argued that SE has no direct relation with PEOU (Govindaraju \& Indriany, 2007; Sternad \& Bobek, 2013). However, other researchers (Hwang, 2011; Shih \& Huang, 2009) found it otherwise. Shih and Huang (2009) observed a positive relationship between SE and PEOU. The differences in their findings on the impact of SE on PEOU may be due to cultural differences as suggested by Hwang (2011). Power distance is a dimension of culture and can be a barrier to SE since it had a significantly negative impact on SE (Hwang, 2011).

Table 1. Variables investigated for affecting technology acceptance of ERP systems

\begin{tabular}{ll}
\hline Variables & Researchers \\
\hline Training & Amoako-Gyampah \& Salam (2004); Lee et al. (2010) \\
Management support & Shih \& Huang (2009) \\
$\begin{array}{l}\text { System capability, user guidance, } \\
\text { learnability }\end{array}$ & Calisir \& Calisir (2004) \\
Enjoyment/cognitive absorption & Mayeh et al. (2014) \\
Complexity & Chang et al. (2008) \\
Self-efficacy (SE) & Govindaraju \& Indriany (2007); Hwang (2011); Shih \& Huang \\
& (2009); Sternad \& Bobek (2013); Venkatesh \& Davis (1996) \\
Computer anxiety & Garača (2011); Shih \& Huang (2009) \\
Interest & Lee et al. (2010) \\
Technical support & Kwak et al. (2012) \\
$\begin{array}{l}\text { Data quality, user manual and sys- } \\
\text { tem performance }\end{array}$ & Sternad \& Bobek (2013) \\
$\begin{array}{l}\text { Project communication } \\
\text { Project champion }\end{array}$ & Amoako-Gyampah (2007); Soto-Acosta et al. (2013) \\
$\begin{array}{l}\text { In-house IT personal knowledge } \\
\text { Personal innovativeness (PIT) }\end{array}$ & Soto-Acosta et al. (2013) \\
$\begin{array}{l}\text { Perceived Informato (2011) } \\
\text { cy (PINT) }\end{array}$ & Govindaraju \& Indriany (2007); Hwang (2011); Sternad \& \\
\hline
\end{tabular}

Agarwal \& Prasad (1998) proposed that personal innovativeness (PIT) is a variable that measures the willingness of any individual to operate something new. PIT has been used as positive stimuli in many ERP system adoption studies and was shown to have a significant direct effect on PEOU (Govindaraju \& Indriany, 2007; Hwang, 2011; Sternad \& Bobek, 2013) and SE (Hwang, 2011). Computer anxiety was found not being significantly negatively related to PEOU and PU (Shih \& Huang, 2009). Garača (2011) also investigated computer anxiety as a variable but the correlation between computer anxiety and user satisfaction was not statistically significant and thus not confirmed. 
Lee et al. (2010) identified that there was a significant relationship between an individual's interest and BIU towards an ERP system. The data quality, user manual, and system performance were considered as system and technological characteristics that impacted the PEOU of an ERP system (Sternad \& Bobek, 2013). Within the organization's IT department, the need for a project champion, project communication (Amoako-Gyampah, 2007; Soto-Acosta et al., 2013), and inhouse IT personal knowledge (Ifinedo, 2011) were added as extensions to the TAM model. The more recent work of Al-Jabri and Roztocki (2014) suggested that perceived information transparency (PINT), which means sharing of data and knowledge, explained the acceptance or rejection of an ERP system.

Apart from the individual and organizational perspectives, some authors proposed to measure the system characteristics and technical support associated with the external variables of TAM. System complexity was also considered but found to have no significant relationship with actual system use (Chang, Cheung, Cheng, \& Yeung, 2008); however, in other research it was found to have a statistically significant impact on PEOU (Bueno \& Salmeron,2008).

\section{Measuring the Usability of ERP Systems}

In the last two decades, several qualitative and quantitative methods and guidelines have been provided by various usability researchers. Jakob Nielsen's (1994) 10 general principles for interaction design were called "heuristics" because they are broad rules of thumb and not specific usability guidelines for designing interfaces. Similarly, the eight golden rules provided by Shneiderman (1996) for user interface design is a qualitative assessment guideline for user interfaces. From a quantitative point of view, the Software Usability Measurement Inventory (SUMI) was proposed to measure a user's satisfaction on any system (Kirakowski, 1996). Brooke (1996) developed another usability scale, called the System Usability Scale (SUS), which was also empirically tested in an ERP setting by Wai-Peng et al. (2015). More recently, a usability measurement scale, called "SUPR-Q" and developed by Sauro (2015), focused on some human factors like trust and loyalty. Very limited research in recent years has focused on quantitative usability criteria and guidelines for ERP systems.

Problems related to the user interface of systems lead to non-acceptance and failure of these systems. Usability is therefore an important quality factor for the acceptance of interactive software applications (Seffah, Donyaee, Kline \& Padda, 2006), and these applications include ERP systems. Ease of use as a factor for ERP system acceptance was investigated by Almajali et al. (2016). Ease of use refers to the user's belief that the technology in question is easy-to-use (F. D. Davis et al., 1989). If a particular part of technology or a complex system is difficult to use, it is unlikely to be used when there is an alternative way. The ISO/IEC 25010 definition of usability is "the capability of the software product to be understood, learned, operated, attractive to the user, and compliant to standards/ guidelines, when used under specific conditions" (ISO, 2011).

Preece, Rogers, and Sharp (2011) describe usability as easy to learn (learnability), effective to use (effectiveness), and enjoyable from the user's perspective.

Three criteria of usability for ERP systems were used in the study by Scholtz, Calitz, and Cilliers (2013), and they are navigation, presentation, and learnability. We chose to utilize these three criteria in this study as well since they have been successfully used in several studies of ERP usability (Singh \& Wesson, 2009; Scholtz et al., 2013). The first criterion, navigation, has been reported as a design issue in several ERP usability studies (Calisir \& Calisir, 2004; Lucas \& Babaian, 2012; Šūpulniece et al., 2013; Singh \& Wesson, 2009). Poor navigation can prevent users and ultimately the organization from obtaining the proper benefits from their ERP system (Matthews, 2008; Maurizio \& Rosemann, 2005). Navigation of a system should be improved by providing guidance for novice users (Surendran, Somarajan, \& Holsing, 2006). 
The second usability criterion is presentation of system functions, which if not designed appropriately would lead to complications in understanding or interpreting the system's outputs. The purpose of the presentation criterion is to determine the appropriateness of the layout of menus, dia$\log$ boxes, controls, and information elements on the data entry screen as well as included in output. These issues are particularly prevalent in ERP systems with their many and complex menu structures (Scholtz et al., 2013). This criterion therefore refers to how well the visual layout is designed and presented, and it is related to the concept of visual attractiveness defined as the system's appearance being attractive to its users, such as the color and nature of the graphical design (ISO, 2001).

The last criterion of usability adopted in this study was learnability, which is defined as the required period that a user takes to learn how to use the system effectively (Nielson, 1994). Learnability is also defined as the ease with which new or novice users can start effective interaction with the system and achieve the maximum performance (Dix, Finlay, Abowd, \& Beale, 2011). Learnability was adopted in this study since it is one of the most commonly cited criteria of usability (Dix et al., 2011; Nielsen, 1994; Seffah et al., 2006; Shneiderman, 1996; Shneiderman et al., 2010), and it is particularly appropriate for ERP systems due to the extensive training they require, the steep learning curve, and the diversity of user experience. Features that make a system easy to use and to learn for novice users could be more complex and cumbersome for more experienced users (Molich \& Nielsen, 1990). The learnability of an ERP system can be improved by providing an introductory interface catered for novice users learning to use the system (Topi et al., 2005). Another way of improving the learnability of ERP systems is to employ in the interface only concepts and language familiar to the user (Galitz, 2007; Hustad \& Olsen, 2011), which in turn improves user satisfaction (Calisir \& Calisir, 2004).

\section{Research Gap}

Our reviewing of the literature revealed that the majority of studies using TAM for ERP evaluation (as listed in Table 1) discussed several human factors of ERP systems, but offered little on guidelines and criteria for the design and evaluation of less complex ERP systems. On the other hand, studies (Scholtz et al., 2013; Singh \& Wesson, 2009) that focused on ERP system usability criteria did not investigate the TAM or extension of it to include usability. This highlights a gap between $\mathrm{HCI} / \mathrm{usability}$ and technology acceptance and the need for research to bridge the gap.

By linking interface usability to end users' intention to use an ERP system, this work contributes to research on ERP implementations and on ERP and other IT usability. This work responds to the call to move beyond individual or organizational constructs as well as beyond using traditional Nielson's heuristics as predictor variables for examining interface usability. The importance of understanding users' perceptions of presentation, navigation, and learnability will lead to positive perceptions of usefulness and ease of use of an ERP system in the post implementation stage, which will in turn improve users' acceptance and adoption of the system.

\section{Research Model and Hypotheses}

For the purpose of this research, the TAM theory was extended to include usability (Figure 1). The general hypothesis is that interface usability (in terms of navigation, presentation, and learnability) will impact the PU and PEOU of an ERP system.

The directly related hypotheses in this study are:

H1: Perceived Usefulness has a positive effect on Attitude Towards Usage of an ERP system.

H2: Perceived Ease of Use has a positive effect on Attitude Towards Usage of an ERP system.

H3: Perceived Usefulness is positively influenced by Perceived Ease of Use. 


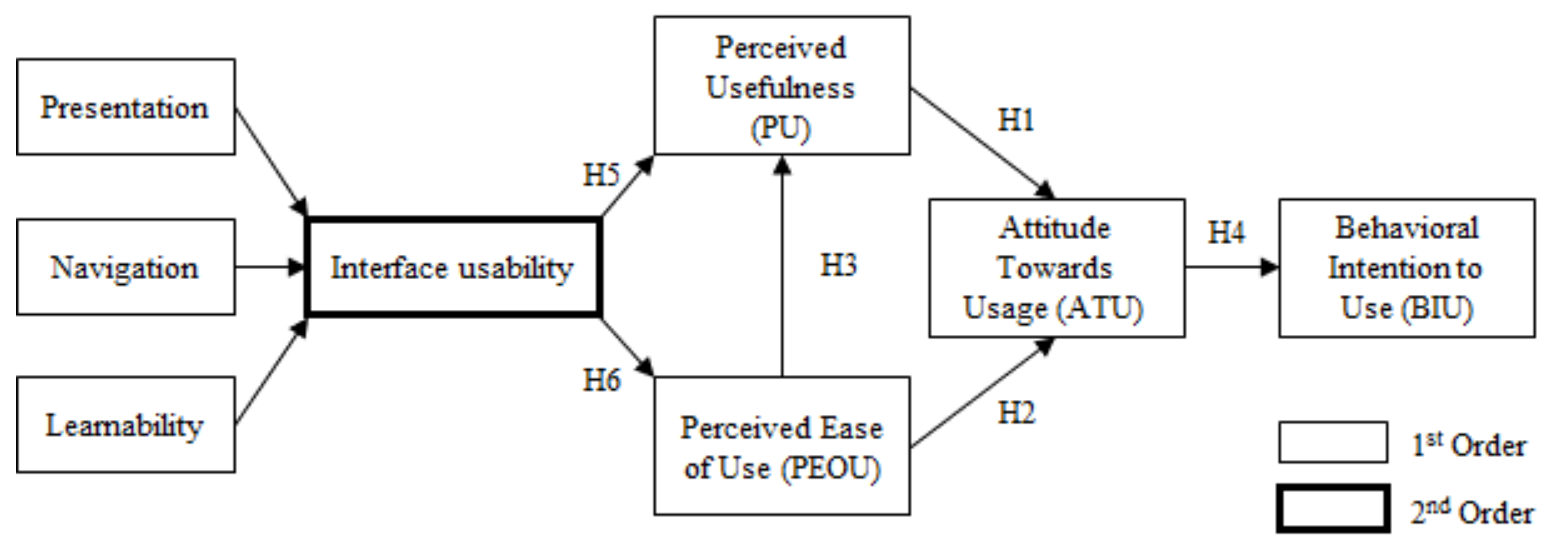

Figure 1. Research model

Amoako-Gyampah (2007) concluded that the users' PE, PEOU, and level of intrinsic involvement are the most important factors that affect their BIU. He also suggested that since an ERP system is mandated technology, actual use should not be considered. So we formulated the hypothesis:

H4: Attitude Towards Usage has a positive effect on the Behavioral Intention to Use an ERP system.

A number of researchers (Calisir, Gumussoy, \& Bayram, 2009; Sūpulniece et al., 2013; Usmanij, Khosla, \& Chu, 2013) have suggested that user satisfaction is one of the key factors leading to the success of an Information System (IS) and that interface usability can be seen as one of the factors that influences end user satisfaction (Babaian, Lucas, \& Topi, 2006; Šupulniece et al., 2013). A user friendly interface decreases system complexity and impacts on user behavior (Bueno \& Salmeron, 2008). Identification of user interface characteristics should be enforced in the implementation stage of an ERP system (Ehie \& Madsen, 2005). Therefore, the fifth and sixth hypotheses of this study are:

H5: Interface usability has a positive effect on Perceived Usefulness of an ERP system.

H6: Interface usability has a positive effect on Perceived Ease of Use of an ERP system.

\section{Research Design \& Methods}

\section{Survey Participants}

A paper-based survey was conducted to explore usability issues that emerged after system implementation, with the questionnaire consisting of two instruments derived from the literature. The survey participants were employees in a renowned, well established organization in the heavy metal manufacturing industry in Bangladesh. For purposes of anonymity, the organization will be referred to as MetalCo in this paper. The random sampling technique suggested by Sekaran (2006) was used as the total population was known. There were 140 ERP users in MetalCo and by using the formula provided by Sekaran (2006), our targeted sample was 103 . The survey was distributed to all available users $(\mathrm{n}=124)$, all of whom operate on a daily basis on different modules of SAP ERP and, therefore, have experience of the system. A response rate of $90 \%$ was obtained since 112 of the 124 users ( $83 \%$ male, $17 \%$ female) completed the survey. A post-hoc power analysis was conducted with medium effect size using $\mathrm{G}^{*}$ power calculator. It shows a power (0.889) greater than .80, which is considered adequate given the typical $\alpha$ level of .05 (Sykes, 2015). 


\section{Instruments}

As noted above, the survey questionnaire is essentially a combination of two measuring instruments, usability measurement and TAM measurement, both adopted from previous studies.

\section{Usability measurement scale}

The usability scale, proposed by Scholtz et al. (2013), which in turn was adapted from the framework proposed by Singh and Wesson (2009), was used in this study to measure the interface usability of the ERP system. The three usability criteria implemented in the scale are navigation, presentation, and learnability (Table 2). Each of these three criteria has several usability attributes to be rated on a positive 5-point Likert scale (where $1=$ Strongly disagree, $2=$ Disagree, $3=$ Slightly agree, $4=$ Agree and $5=$ Strongly Agree) .

Table 2. Usability criteria and measurement items

\begin{tabular}{ll}
\hline Navigation \\
\hline NEV1 & Information can be easily accessed \\
NEV2 & Functionality can be found quickly and easily \\
NEV3 & The user interface supports efficient and accurate navigation of the system \\
NEV4 & There is a correlation between the searched item and the required item \\
\hline Presentation \\
\begin{tabular}{ll} 
PRES1 & The visual layout is well designed \\
PRES2 & The information provided by the system is timely, accurate, complete and understandable \\
PRES3 & $\begin{array}{l}\text { The layout of menus, dialog boxes and controls are easy to understand and interpret and well } \\
\text { structured }\end{array}$ \\
\hline Learnability \\
\hline LER1
\end{tabular} $\begin{array}{l}\text { A user can learn how to use the system without a long introduction } \\
\text { LER2 }\end{array} \quad \begin{array}{l}\text { The various functions of the system can be identified by exploration } \\
\text { There is sufficient on-line help to support the learning process }\end{array}$ \\
\hline
\end{tabular}

\section{TAM measurement}

The TAM questionnaire from F. D. Davis et al. (1989) was adopted for measuring PU and PEOU, and it is supplemented with additional questions drawing on more recent literature to measure ATU and BIU. All the constructs in the research model were therefore operationalized using standard scales from past literature. In summary, our TAM measurement instrument consists of 20 items in total, with five items for each of the four constructs (PU, PEOU, ATU, and BIU), as listed in Table 3. The response scale for all items is a positive 5-point Likert scale (Lam \& Klockars, 1982), where 1 = Strongly disagree, $2=$ Disagree, $3=$ Slightly agree, $4=$ Agree, $5=$ Strongly Agree. 
An Analysis of the Impact of Usability on Technology Acceptance in ERP Settings

Table 3. Questionnaire blocks of different constructs of TAM

\begin{tabular}{|c|c|c|}
\hline \multicolumn{3}{|c|}{ Perceived Usefulness (PU) } \\
\hline $\begin{array}{l}\text { PU1 } \\
\end{array}$ & Using the ERP system enhanced my effectiveness at work & \multirow[t]{5}{*}{ F. D. Davis et al. (1989) } \\
\hline PU2 & Using the ERP system improved my performance & \\
\hline PU3 & Using the ERP system increased my productivity at work & \\
\hline PU4 & $\begin{array}{l}\text { Using the ERP system enabled me to accomplish tasks more } \\
\text { quickly }\end{array}$ & \\
\hline PU5 & I found using the ERP system useful & \\
\hline \multicolumn{3}{|c|}{ Perceived Ease of Use (PEOU) } \\
\hline PEOU1 & Overall, I found the ERP system interface easy to use & \multirow[t]{5}{*}{ F. D. Davis et al. (1989) } \\
\hline PEOU2 & Learning to use the ERP system interface is easy to me & \\
\hline PEOU3 & $\begin{array}{l}\text { Interaction with the ERP system interface is clear and under- } \\
\text { standable }\end{array}$ & \\
\hline PEOU4 & It was easy for me to become skillful at using the ERP system & \\
\hline PEOU5 & I found the ERP system interface was flexible to interact with & \\
\hline \multicolumn{3}{|c|}{ Attitude Towards Usage (ATU) } \\
\hline ATU1 & $\begin{array}{l}\text { I generally have a favorable attitude toward using the ERP } \\
\text { system }\end{array}$ & Al-Jabri \& Roztocki (2014) \\
\hline ATU2 & I believe it is a good idea to use the ERP system for my work & Al-Jabri \& Roztocki (2014) \\
\hline ATU3 & I like the idea of using the ERP system & Choi, Kim, \& Kim. (2007) \\
\hline ATU4 & Using the ERP System provided me with a lot of enjoyment & Al-Jabri \& Roztocki (2014) \\
\hline ATU5 & Overall, I enjoyed using the ERP system & Al-Jabri \& Roztocki (2014) \\
\hline \multicolumn{3}{|c|}{ Behavioral Intention to Use (BIU) } \\
\hline BIU1 & I intend to use the ERP system always & Mayeh et al. (2014) \\
\hline BIU2 & $\begin{array}{l}\text { I intend to use the ERP system frequently rather than manual } \\
\text { way }\end{array}$ & Mayeh et al. (2014) \\
\hline BIU3 & I intend to use the ERP system as often as possible & Mayeh et al. (2014) \\
\hline BIU4 & I plan to use more modules in the ERP system in the future & Calisir et al. (2009) \\
\hline BIU5 & I expect my use of the ERP system to continue in the future & Calisir et al. (2009) \\
\hline
\end{tabular}

\section{Data Analysis and Results}

\section{Data Analysis}

The second generation statistical analysis technique called Structural Equation Modeling (SEM) was used to test the theoretical model. SEM has recently grown very popular in IS research (Aziz \& Kamaludin 2014; Roberts \& Grover, 2009). The Partial Least Squares (PLS) based SEM (PLSSEM) provides a visual display of the relationship between hypotheses and variables (Hair, Ringle, \& Sarstedt, 2011). PLS-SEM evaluates path coefficients that make the most of $\mathrm{R}^{2}$ values of 
the variables. PLS can control complexity with the correction of various models and produce high levels of statistics with small sample sizes. The PLS approach follows two levels of processing. The first level evaluates the measurement instrument by investigating the reliability and discriminate validity of constructs. The second level determines the significance level of path coefficients within the model to test the associated hypotheses (Esposito Vinzi, Chin, Henseler, \& Wang, 2010). In the case of interface usability, the higher order construct model was used as suggested by several researchers (MacKenzie, Podsakoff, \& Jarvis, 2005; Petter, Straub, \& Rai, 2006).

The Smart PLS Version 3.0 software was used to analyze the data as done in several other studies (Al-Jabri \& Roztocki, 2014; Nwankpa \& Roumani, 2014) to measure ERP adoption. Following the recommendations by other researchers (Chin, 2010; Gil-Garcia, 2008), the bootstrapping method (500 resample) was used to determine the significance levels of loadings, weights, and path coefficients.

\section{Common Method Bias}

The sample might be subject to common method variance (CMV), since the dependent and independent variables were measured from the same participants (Podsakoff, MacKenzie, Lee, \& Podsakoff, 2003). Therefore, we conducted Harman's single factor test, following the suggestions by Sharma, Ringle, and Sarstedt (2009) and Lin, Huang, and Hsu (2015). The results show that the restricted extraction of a single factor only explains $39.16 \%$ of the variance, implying that the data did not have a CMV problem.

\section{Measurement Model}

In Table 4, the results of loadings, Average Variance Extracted (AVE) and Composite Reliability (CR) measures of all items for first order constructs are reported. The measurement would be acceptable if the AVE for each construct is greater than 0.50 (Nunnally \& Bernstein, 1994) and CR is greater than 0.80 (Chin, 2010). In this case, all items are loaded highly on their own latent variable, and thus all measurements have satisfactory levels of reliability.

Table 4. Measurement model of first-order constructs

\begin{tabular}{llllllll}
\hline Items & Loadings & AVE & CR & Mean & Std. Dev & Skewness & Kurtosis \\
\hline $1^{\text {st }}$ order Constructs (Reflective) & & & & & \\
ATU2 & 0.798 & & & 4.14 & 1.21 & 1.35 & 0.89 \\
ATU3 & 0.754 & 0.609 & 0.823 & 4.35 & 1.04 & 1.40 & 0.75 \\
ATU5 & 0.787 & & & 4.04 & 1.18 & 0.79 & -0.80 \\
BIU1 & 0.638 & & & 3.97 & 1.09 & -0.66 & -0.91 \\
BIU2 & 0.627 & & & 3.79 & 1.26 & -0.659 & -0.76 \\
BIU3 & 0.755 & & & 3.99 & 1.06 & -0.673 & -0.81 \\
BIU4 & 0.781 & 0.513 & 0.839 & 4.09 & 1.19 & -0.960 & -0.58 \\
BIU5 & 0.766 & & & 4.20 & 1.13 & -1.12 & -0.14 \\
LER1 & 0.868 & & & 2.41 & 0.665 & -0.50 & -0.46 \\
LER2 & 0.826 & 0.661 & 0.854 & 2.32 & 0.674 & -.031 & -0.55 \\
LER3 & 0.740 & & & 2.27 & 0.671 & -0.19 & -0.51 \\
NEV2 & 0.853 & 0.765 & 0.867 & 2.46 & 0.721 & -0.64 & -0.47
\end{tabular}


An Analysis of the Impact of Usability on Technology Acceptance in ERP Settings

\begin{tabular}{llllllll}
\hline Items & Loadings & AVE & CR & Mean & Std. Dev & Skewness & Kurtosis \\
\hline NEV3 & 0.896 & & & 2.40 & 0.726 & -0.39 & -0.50 \\
PEOU1 & 0.640 & & & 3.5 & 1.22 & -0.135 & -1.48 \\
PEOU3 & 0.776 & 0.591 & 0.851 & 3.49 & 1,090 & -0.147 & -0.80 \\
PEOU4 & 0.789 & & & 3.78 & 1.113 & -0.424 & -1.018 \\
PEOU5 & 0.856 & & & 3.89 & 1.093 & -0.500 & -1.09 \\
PRS1 & 0.785 & & & 2.44 & 0.745 & -0.11 & -0.32 \\
PRS2 & 0.793 & 0.665 & 0.856 & 2.26 & 0.781 & -0.54 & -0.50 \\
PRS3 & 0.866 & & & 2.29 & 0.687 & -0.25 & -0.60 \\
PU2 & 0.889 & & & 3.97 & 1.061 & -0.776 & -0.428 \\
PU3 & 0.824 & 0.710 & 0.880 & 4.04 & 1.082 & -0.811 & -0.491 \\
PU5 & 0.814 & & & 3.96 & 1.138 & -0.675 & -0.867 \\
\hline
\end{tabular}

Note: ${ }^{a} \mathrm{AVE}=$ (summation of squared factor loadings) / (summation of squared factor loadings) (summation of error variances) ${ }^{b} \mathrm{CR}=$ (square of the summation of the factor loadings) / [(square of the summation of the factor loadings) + (square of the summation of the error variances)]

(To get better reliability and discriminant validity lower loadings Item PU1, PU4, NEV1, NEV4, PEOU2, ATU1 and ATU4 were dropped)

Table 5. Measurement model of second level constructs (formative)

\begin{tabular}{llll}
\hline Usability & Weights & t value & VIF \\
\hline Learnability & 0.394 & $18.497^{* * *}$ & 2.692 \\
Presentation & 0.469 & $26.984^{* * *}$ & 2.955 \\
Navigation & 0.232 & $16.180^{* * *}$ & 2.107 \\
\hline
\end{tabular}

For second order constructs, Table 5 shows that the VIF values for learnability, presentation and navigation are all below the threshold of 3.33 (Diamantopoulos \& Siguaw, 2006). The results therefore did not indicate a multicollinearity problem. As show in Table 6 , the analysis of discriminate validity shows a reasonably higher loading of each item on its intended construct than on any other constructs.

Table 6. Discriminate validity of first-order constructs

\begin{tabular}{llllllll}
\hline & ATU & BIU & LER & NEV & PEOU & PRS & PU \\
\hline ATU & 0.780 & & & & & & \\
BIU & 0.719 & 0.717 & & & & & \\
LER & 0.615 & 0.600 & 0.813 & & & & \\
NEV & 0.534 & 0.553 & 0.661 & 0.875 & & & \\
PEOU & 0.646 & 0.583 & 0.669 & 0.553 & 0.769 & & \\
PRS & 0.567 & 0.685 & 0.775 & 0.700 & 0.694 & 0.816 & \\
PU & 0.755 & 0.660 & 0.685 & 0.481 & 0.765 & 0.654 & 0.843
\end{tabular}

Note: Diagonals represent the square root of AVE while the other entries represent the squared correlations. 
Multicollinearity among the variables was also measured since high correlations were observed between ATU and BIU (0.719), BIU and PRS (0.685), LER and PRS (0.775). The calculation yielded variation inflation factor (VIF) values in the range of 1.279 and 2.884 , which is less than 10. Therefore, it is confirmed that no multicollinearity exists among the constructs (Bock, Zmud, Kim, \& Lee, 2005; Neter, Kutner, Nachtsheim, \& Wasserman, 1996).

\section{Structural Model}

The structural model is presented in Figure 2, with annotation of path coefficients $(\beta)$ and portions of variance explained $\left(\mathrm{R}^{2}\right)$, and the results of hypothesis testing by determining the significance levels of path coefficients are summarized in Table 7.

Specifically, strong and statistically significant evidence was found in support of hypothesis $\mathrm{H} 1$ (PU $\rightarrow$ ATU, $\beta=0.629, p<0.01$ ), which is consistent with the findings of Soto-Acosta et al. (2013). Similarly, statistically significant support is found for $\mathrm{H} 3$ (PEOU $\rightarrow \mathrm{PU}, \beta=0.543, p<0.01$ ), and this confirms previous studies reporting a positive effect of PEOU on PU (Agrifoglio \& Metallo, 2010; Calisir \& Calisir, 2004; Escobar-Rodríguez \& Bartual-Sopena, 2014). In addition, the results also revealed that ATU positively influences users' BIU of ERP systems, and H4 is supported as well (ATU $\rightarrow$ BIU, $\beta=0.719, p<0.01$ ), confirming the findings of previous researchers (Ramayah \& Lo, 2007; Soto-Acosta et al., 2013). However, H2 (PEOU $\rightarrow$ ATU) is not supported since $\beta=0.163$ and $p>0.05$.

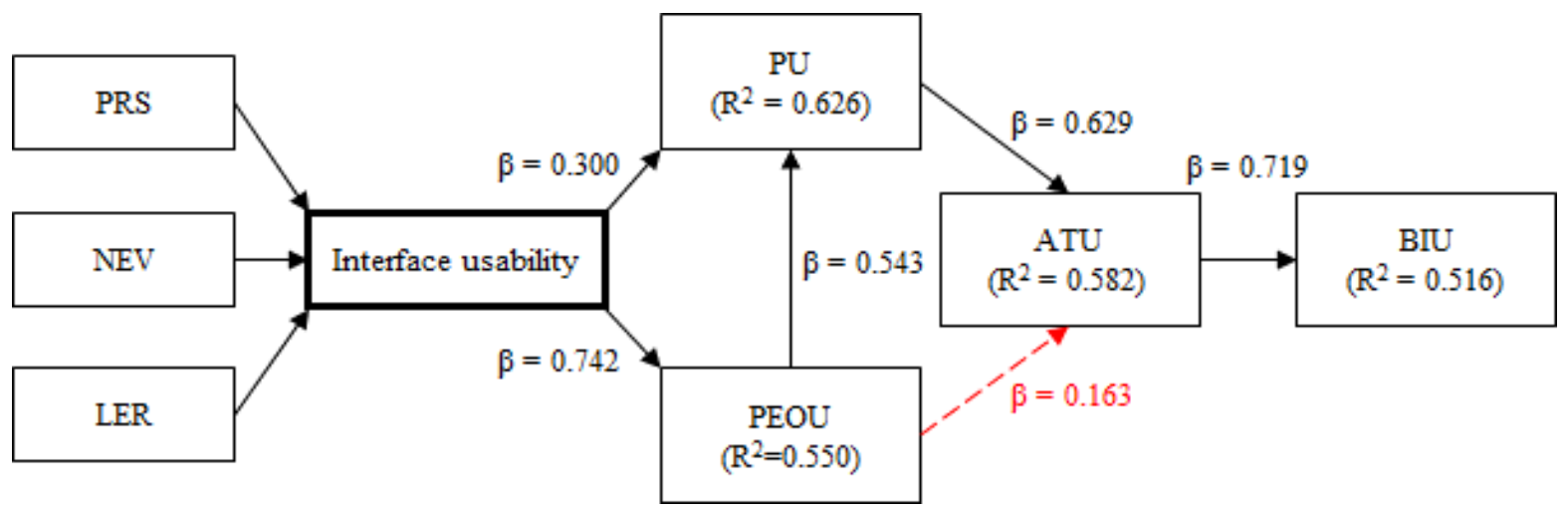

Figure 2. Results of evaluating the structural model

Table 7. Results of hypothesis testing

\begin{tabular}{lllll}
\hline Hypothesis & Relation & Path co-efficient $(\boldsymbol{\beta})$ & t value & Result \\
\hline H1 & PU $\rightarrow$ ATU & 0.629 & 6.182 & Supported** \\
H2 & PEOU $\rightarrow$ ATU & 0.163 & 1.809 & Not supported \\
H3 & PEOU $\rightarrow$ PU & 0.543 & 6.182 & Supported** \\
H4 & ATU $\rightarrow$ BIU & 0.719 & 13.626 & Supported** \\
H5 & Usability $\rightarrow$ PU & 0.300 & 2.697 & Supported** \\
H6 & Usability $\rightarrow$ PEOU & 0.742 & 18.828 & Supported** \\
\hline
\end{tabular}

Note: $* * \mathrm{p}<0.01$, 
Our study found significant evidence supporting hypotheses H5 ( $\beta=0.300, p<0.01)$ and H6 $(\beta=$ $0.742, p<0.01)$ which address the direct impact of interface usability, meaning that a higher level of ERP system usability has positive impact on PU and PEOU of the system. This result is similar to the studies of Calisir and Calisir (2004) and Holden and Rada (2011); however, Holden and Rada (2011) measured usability as a part of PEOU and Calisir and Calisir (2004) focused on system capability and learnability. Neither of these two studies used standard HCI techniques for evaluating specific usability criteria (presentation, navigation, learnability).

\section{Findings and Discussion}

At the time of writing, no previous evidence could be found on the impact of ERP system usability on PU and PEOU and ultimately on ATU and BIU in the context of a developing country such as Bangladesh. The results of the survey supported hypothesis $\mathrm{H} 1$ since a significant relationship was revealed between PU and ATU, thus confirming the findings of previous research (Al-Jabri \& Roztocki, 2014; Escobar-Rodríguez \& Bartual-Sopena, 2014; Sternad \& Bobek, 2013). However, the impact of PEOU on ATU was not significant and H2 was not supported. This result is surprising and does not align with the traditional TAM model by F. D. Davis et al. (1989). On the other hand, hypotheses $\mathrm{H} 3$ and $\mathrm{H} 4$ are supported, which is in agreement with the research findings of Bueno and Salmeron (2008), Calisir et al. (2009), and Samander and Abdul Rahman (2014). The results seem to reinforce the rather important observation that if things are not perceived as easy to use then they are not considered useful. The findings also show that if the attitude to use a system is negative, people will simply not use it.

\section{Theoretical and Practical Contributions}

This study made several theoretical contributions to the field of ERP usability research. This paper contributes to the body of work focused on improved understanding of ERP implementations and ERP usability. It complements the micro-level examinations of ERP adoption by building on our understanding of the individual users' experience. This research identified the strengths and weaknesses of usability in terms of navigation, presentation, and learnability, and it complements existing IS and HCI research by investigating the role of usability in the context of ERP acceptance.

It is interesting to note the research finding that interface usability can positively affect the users' perception of usefulness, ease of use, and attitude towards an ERP system. Specifically, interface usability (in terms of navigation, learnability and presentation) could lead to a significantly higher rating of perceptions and attitudes of SAP ERP users.

Previous research focused on factors related to attitude and behavior of users, and only a few studies have examined the link between interface usability and its impact on user acceptance of ERP systems. It is in this regard that this research made a primary contribution by extending the traditional TAM theory to include interface usability as an external variable along with the three criteria of usability assessment (navigation, presentation, and learnability). The results also verified the use of these criteria for designing and evaluating ERP systems, as suggested by Scholtz et al. (2013). It follows naturally that by improving the navigation, presentation, and learnability of an ERP system, the PEOU and PU of the system will improve, which in turn will lead to increased usage of the system. Several guidelines regarding improving the navigation, presentation, and learnability of ERP systems were confirmed by the research participants in their responses to the survey.

This work has practical implications for practitioners and designers. From this research, stakeholders of ERP systems, particularly SAP partners, can gain a clearer understanding of the factors influencing ERP usability, ERP adoption, and ultimately ERP project success. The research find- 
ings may serve for ERP designers as guidelines for improving the usability of the user interface by focusing on the navigation, presentation, and learnability of the system, thereby ultimately increasing users' intention to use the ERP system. It is argued that the issues and problems in learnability are mostly due to lack of (or limited) help and support embedded in the interface of an ERP system and that this would cause the industry to face huge costs (in terms of time and money) for training "after" the system has been implemented and deployed. This study has shown the importance of interface usability to ERP specialist and ERP designers/developers in Bangladesh, and the recommendations from this study can assist SAP AG and other ERP system vendors to rethink usability when developing their products.

\section{Methodological Contributions}

In this research, SEM was used to measure the relationship among the variables of the proposed research model. There are several reasons for using SEM. Firstly, SEM allows researchers to analyze a complex model with multiple independent and dependent variables comprehensively and simultaneously. As a result, IS, business management, and social science researchers are using this technique for their research (Gefen, Straub, \& Boudreau, 2000; Kline 2005). Secondly, higher order variable modelling (e.g., $2^{\text {nd }}$ order formative measurement for usability as done in this study) can be easily done in SEM (Edwards, 2001), thereby motivating IS researchers to measure their constructs, develop research model, or test theories.

This paper reports on a quantitative analysis of the proposed model of ERP system adoption using SEM. The PLS approach from SEM was implemented, which is an appropriate method for testing a multivariate, multi-path model. Methodologically it reduces the risk of common method bias by the implementation of Harman's single factor as suggested by Podsakoff et al. (2003). The study therefore also offers contributions to the literature on the use of PLS in studies of manufacturing industries.

\section{Conclusions}

There are some limitations of this study due to time and budget constraints. Firstly, the sample size was relatively small, and the survey was distributed only in one company. Secondly, control variables like age, education level, staff seniority, and gender were not considered in this research although they were suggested by other researchers (Burton-Jones, Storey, Sugumaran, \& Ahluwalia, 2005; Mathieson, Peacock, \& Chin, 2001). Further, the users' perceptions, memory abilities, and reasoning skills are cognitive abilities. Again, cognitive style is a fundamental individual characteristic and refers to consistent individual differences in their preference of ways of organizing and processing information and experience. Usability of any IT is combined with both technology and human factors. Therefore, the influence of technology induced stress (Ayyagari, Grover, \& Purvis, 2011) might impact interface usability and technology adoption, which should be investigated in future research. Since usability deals with human behaviors, longitudinal studies should be conducted as well to observe the changing of intention to use over time.

This study helps us to gain a better understanding of how attitude is perceived and processed by users by producing empirical evidence on the impact of interface usability. We believe this is a vital contribution to the profession of system developers and managers worldwide since their ultimate aim is to improve system usability, upon which the whole economy relies. 


\section{References}

Agarwal, R. \& Prasad, J. (1998). A conceptual and operational definition of personal innovativeness in the domain of information technology. Information Systems Research, 9(2), 204-215.

Agrifoglio, R. \& Metallo, C. (2010). ERP acceptance: The role of affective commitment, in D'Atri, A., De Marco, M., Braccini, A.M. \& Cabiddu. F. (Eds.), Management of the Interconnected World, Berlin: Physica-Verlag,

Almajali, D. A., Masa'deh, R. E., \& Tarhini, A. (2016). Antecedents of ERP systems implementation success: A Study on Jordanian Healthcare Sector. Journal of Enterprise Information Management, 29(4), $549-565$.

Almahamid, S., \& Awsi, O. (2015). Perceived organizational ERP benefits for SMEs: Middle Eastern perspective. Interdisciplinary Journal of Information, Knowledge \& Management, 10, 145-172.

Albert, W. \& Tullis, T. (2013). Measuring the user experience: Collecting, analyzing, and presenting usability metrics. Waltham, MA: Morgan Kaufmann.

Ali, B.M. \& Younes, B. (2013). The impact of Information Systems on user performance: An Exploratory Study. Journal of Knowledge Management, Economics and Information Technology, 3(2).

Al-Jabri, I.M. \& Roztocki, N. (2014). Adoption of ERP systems: does information transparency matter? Telematics and Informatics, 32(2),300-310.

Amoako-Gyampah, K. (2007). Perceived Usefulness, User involvement and behavioral intention: An empirical study of ERP implementation. Computers in Human Behavior, 23(3), 1232-1248.

Amoako-Gyampah, K. \& Salam, A.F. (2004). An extension of the technology acceptance model in an ERP implementation environment. Information \& Management, 41(6), 731-745.

Ayyagari, R., Grover, V., \& Purvis, R. (2011). Technostress: technological antecedents and implications. MIS Quarterly, 35(4), 831-858.

Aziz, N.S. \& Kamaludin, A. (2014). Assessing website usability attributes using Partial Least Squares. International Journal of Information and Electronics Engineering, 4(2), 137-144.

Babaian, T., Lucas, W. \& Topi, H. (2006). Improving ERP usability through user-system collaboration. International Journal of Enterprise Information Systems, 2(3), 10-23.

Bock, G.W., Zmud, R.W., Kim, Y.G. \& Lee, J.N. (2005), Behavioral intention formation in knowledge sharing: Examining the roles of extrinsic motivators, social-psychological forces, and organizational climate, MIS Quarterly, 29(1), 87-111.

Brooke, J. (1996). SUS-A quick and dirty usability scale. Usability evaluation in industry. 189(194), 4-7.

Bueno, S. \& Salmeron, J.L. (2008). TAM-based success modeling in ERP. Interacting with Computers, 20(6), 515-523.

Burton-Jones, A., Storey, V.C., Sugumaran, V. \& Ahluwalia, P. (2005). A semiotic metrics suite for assessing the quality of ontologies. Data \& Knowledge Engineering, 55(1), 84-102.

Business Wire. (2011). "Bangladesh business applications market shifting from indigenous to global brands". Retrieved September 25, 2014 from http://www.businesswire.com/news/home/20111122005105/en/Bangladesh-Business-ApplicationsMarket-Shifting-Indigenous-Global\#.VE1HxPmUdfw

Calisir, F. \& Calisir, F. (2004). The relation of interface usability characteristics, perceived usefulness, and perceived ease of use to end-user satisfaction with enterprise resource planning (ERP) systems, Computers in Human Behavior, 20(4): 505-515.

Calisir, F., Gumussoy, C.A. \& Bayram, A. (2009). Predicting the behavioral intention to use enterprise resource planning systems: An exploratory extension of the technology acceptance model, Management Research News, 32(7): 597-613. 
Ceaparu, I., Lazar, J., Bessiere, K., Robinson, J. \& Shneiderman, B. (2004), Determining causes and severity of end-user frustration, International Journal of Human-Computer Interaction, 17(3): 333-356.

Chang, M.K., Cheung, W., Cheng, C.H. \& Yeung, J.H.Y. (2008). Understanding ERP system adoption from the user's perspective. International Journal of Production Economics, 113(2), 928-942.

Chin, W.W. (2010): Bootstrap cross-validation indices for PLS path model assessment. In: Esposito Vinzi, V., Chin,W., Hensler, J., Wold, H. (eds.) Handbook of Partial Least Squares, pp. 83-97. Heidelberg: Springer.

Choi, D.H., Kim, J. \& Kim, S.H. (2007). ERP training with a web-based electronic learning system: The flow theory perspective. International Journal of Human-Computer Studies, 65(3), 223-243.

Davis, C.H. \& Comeau, J. (2004). Enterprise integration in business education: Design and outcomes of a capstone ERP-based undergraduate e-business management course. Journal of Information Systems Education, 15(3), 287-300.

Davis, F.D., Bagozzi, R.P. \& Warshaw, P.R. (1989). User acceptance of computer technology: A comparison of two theoretical models. Management Science, 35(8), 982-1003.

Diamantopoulos, A., \& Siguaw, J. A. (2006). Formative versus reflective indicators in organizational measure development: A comparison and empirical illustration. British Journal of Management, 17(4), 263-282.

Dix, A., Finlay, J., Abowd, G.D. \& Beale, R. (2011). Human-Computer Interaction (3 ${ }^{\text {rd }}$ edition). Canada: Prentice-Hall.

Edwards, J. R. (2001). Multidimensional constructs in organizational behavior research: An integrative analytical framework. Organizational Research Methods, 4(2), 144-192.

Ehie, I.C. \& Madsen, M. (2005). Identifying critical issues in enterprise resource planning (ERP) implementation. Computers in Industry, 56(6): 545-557.

Eid, T. \& Granetto, B.F. (2014), "Forecast Analysis: Enterprise Application Software, Worldwide, 2Q14 Update", Gartner, Inc.

Escobar-Rodríguez, T. \& Bartual-Sopena, L. (2014). "Impact of cultural factors on attitude toward using ERP systems in public hospitals". Retrieved June 2015 from http://www.sciencedirect.com/science/article/pii/S1138489114000259

Esposito Vinzi, V., Chin, W.W., Henseler, J. \& Wang, H. (2010). Handbook of Partial Least Squares: Concepts, methods and applications, Berlin, Heidelberg: Springer.

Faisal, C.M.N., Faridi, M.S., Javed, Z. \& Shahid, M. (2012). Users' adoptive behavior towards the ERP system. Intelligent Information Management, 4(3), 75-79.

Fishbein, M. \& Ajzen, I. (1975). Belief, attitude, intention and behavior: An Introduction to theory and research. Reading, MA: Addison-Wesley.

Forcht, K.A., Kieschnick, E., Aldridge, A. \& Shorter, J.D. (2007). Implementing Enterprise Resource Planning (ERP) for strategic competitive advantage, Issues in Information Systems, 8(2), 425-429.

Galitz, W.O. (2007). The essential guide to user interface design: An Introduction to GUI Design Principles and Techniques, Indianapolis, IN: Wiley Publishing.

Garača, Ž. (2011). Factors related to the intended use of ERP systems. Management: Journal of Contemporary Management Issues, 16(2), 23-42.

Gefen, D., Straub, D., \& Boudreau, M. C. (2000). Structural equation modeling and regression: Guidelines for research practice. Communications of the Association for Information Systems. 4(1), 7.

Gil-Garcia, J. R. (2008). Using partial least squares in digital government research. Handbook of research on public information technology. Hershey: Idea Group. 
An Analysis of the Impact of Usability on Technology Acceptance in ERP Settings

Govindaraju, R. \& Indriany, N. (2007). A study on ERP system acceptance based on Technology Acceptance Model. Proceedings of the $2^{\text {nd }}$ International Conference on Operations and Supply Chain Management. Bangkok, Thailand, 18-20 May 2007.

Great Speculations. (2014). "Factors Responsible For Our \$95 SAP Price Estimate". Retrieved September 2014 from http://www.forbes.com/sites/greatspeculations/2014/05/16/factors-responsible-for-our-95sap-price-estimate/

Grigera, J., Garrido, A., Rivero, J. M., \& Rossi, G. (2017). Automatic detection of usability smells in web applications. International Journal of Human-Computer Studies, 97, 129-148.

Gumussoy, C.A., Calisir, F. \& Bayram, A. (2007), "Understanding the behavioral intention to use ERP systems: An extended technology acceptance model”, in 2007 IEEE International Conference on Industrial Engineering and Engineering Management in Singapore, 2-4 December 2007, IEEE, www.ieee.org, pp. 2024-2028.

Hair, J.F., Ringle, C.M. \& Sarstedt, M. (2011). PLS-SEM: Indeed a silver bullet. Journal of Marketing Theory and Practice, 19(2), 139-152.

Hawari, A. \& Heeks, R. (2010). Explaining ERP failure in a developing country: A Jordanian case study. Journal of Enterprise Information Management, 23(2): 135-160.

Hendrickson, A.R., Massey, P.D. \& Cronan, T.P. (1993). On the test-retest reliability of perceived usefulness and perceived ease of use scales. MIS Quarterly, 17(2), 227-230.

Holden, H. \& Rada, R. (2011). Understanding the influence of perceived usability and technology selfefficacy on teachers' technology acceptance. Journal of Research on Technology in Education, 43(4), $343-367$.

Huang, S.Y., Huang, S.M., Wu, T.H. \& Lin, W.K. (2009). Process efficiency of the enterprise resource planning adoption. Industrial Management \& Data Systems, 109(8), 1085-1100.

Hustad, E. \& Olsen, D.H. (2011). Teaching enterprise systems in Higher Education: The learning context triangle. Proceedings of the $8^{\text {th }}$ International Conference on Enterprise Systems, Accounting and Logistics.

Hwang, Y. (2005). Investigating enterprise systems adoption: uncertainty avoidance, intrinsic motivation, and the technology acceptance model. European Journal of Information Systems, 14(2), 150-161.

Hwang, Y. (2011). Investigating the influence of cultural orientation and innovativeness on ERP adoption. Journal of Global Information Technology Management, 14(3),54-74.

Ifinedo, P. (2011). Examining the influences of external expertise and in-house computer/IT knowledge on ERP system success. Journal of Systems and Software, 84(2), 2065-2078.

Imran, R. (2013). "SAP Bangladesh - The most prospect sector". Retrieved September 2014 from http://bgrajib.blogspot.com/2013/03/sap-bangladesh-most-prospect-sector.html

ISO (2001). ISO 9126-1 Product Quality Part 1: Quality Model. International Standards Organization (ISO). Retrieved April 2016 from http://www.iso.org/iso/iso catalogue/catalogue tc/catalogue detail.htm?csnumber=16876

ISO (2011). ISO/IEC 25010, International Organization for Standardization, ISO, Systems and software engineering - SquaRE - Software product Quality Requirements and Evaluation - System and Software Quality Models (2011)

Kimberling, E. (2012). The commoditization of ERP systems: Same old song and dance?. Retrieved April 2015 from http://panorama-consulting.com/the-commoditization-of-erp-systems-same-old-song-anddance/

Kirakowski, J. (1996). The software usability measurement inventory: background and usage. Usability evaluation in industry, 169-178. 
Kline, R.B. (2005). Principles and practice of structural equation modeling (2nd Edition). New York: The Guilford Press.

Kwak, Y.H., Park, J., Chung, B.Y. \& Ghosh, S. (2012). Understanding end-users' acceptance of Enterprise Resource Planning (ERP) system in project-based sectors. IEEE Transactions on Engineering Management, 59(2), 266-277.

Lam, T.C.M. \& Klockars, A.J. (1982). Anchor point effects on the equivalence of questionnaire items, Journal of Educational Measurement, 19(4), 317-322.

Lambeck, C., Fohrholz, C., Leyh, C., Šūpulniece, I. \& Müller, R. (2014). Commonalities and contrasts: An investigation of ERP usability in a comparative user study. Proceedings of the $22^{\text {nd }}$ European Conference on Information Systems. Tel Aviv, Israel, 9-11 June 2014.

Lee, D., Lee, S.M., Olson, D.L. \& Chung, S.H. (2010). The effect of organizational support on ERP implementation. Industrial Management \& Data Systems, 110(2), 269-283.

Lin, T. C., Huang, S. L., \& Hsu, C. J. (2015). A dual-factor model of loyalty to IT product-The case of smartphones. International Journal of Information Management, 35(2), 215-228.

Lucas, W. \& Babaian, T. (2012). "Implementing design principles for collaborative ERP systems", in Peffers, K., Rothenberger, M. \& Kuechler, B. (Eds.), Design Science Research in Information Systems. Advances in Theory and Practice. Berlin, Heidelberg: Springer

MacKenzie, S.B., Podsakoff, P.M. \& Jarvis, C.B. (2005). The problem of measurement model misspecification in behavioral and organizational research and some recommended solutions. Journal of Applied Psychology, 90(4), 710-730.

Mathieson, K., Peacock, E. \& Chin, W.W. (2001). Extending the Technology Acceptance Model: The influence of perceived user resources. ACM SigMIS Database. 32(3), 86-112.

Matthews, D. (2008). Usability as an ERP selection criteria. IFS White Paper. MIT's Sloan Management Review, Retrieved July 02, 2015 from http://decoder.meritalk.com/uploads_legacy/whitepapers/WP$\underline{\text { Usability.pdf }}$

Maurizio, A. \& Rosemann, M. (2005). SAP-Related Education - Status Quo and Experience. Journal of Information Systems Education, 16(4), 437-453.

Mayeh, M., Ramayah, T. \& Popa, S. (2014). The role of absorptive capacity in the usage of a complex information system: The case of the enterprise information system. Journal of Universal Computer Science, 20(6), 826-841.

Molich, R., \& Nielsen, J. (1990). Improving a human-computer dialogue. Communications of the ACM, 33(3), 338-348.

Motiwalla, L. F., \& Thompson, J. (2012). Enterprise systems for management. Boston, MA: Pearson.

Mukaddes, A.M.M., Chowdhury, N.F.A. \& Uddin, M.M. (2010). A model for automatic preventive maintenance scheduling and an application database software. Proceedings of the 2010 International Conference on Industrial Engineering and Operations Management. Dhaka, Bangladesh, 9-10 January 2010.

Neter, J., Kutner, M.H., Nachtsheim, C.J. \& Wasserman, W. (1996). Applied Linear Statistical Models, Chicago, IL: Irwin.

Nielsen, J. (1994). Enhancing the explanatory power of usability heuristics. Proceedings of the SIGCHI Conference on Human Factors in Computing Systems. ACM, New York, pp. 152-158.

Nunnally, J.C. \& Bernstein, I.H. (1994). The assessment of reliability. In Nunnally, J.C. (Ed.), Psychometric theory, New York, NY: McGraw-Hill.

Nwankpa, J. \& Roumani, Y. (2014). Understanding the link between organizational learning capability and ERP system usage: An Empirical Examination. Computers in Human Behavior, 33, 224-234. 
An Analysis of the Impact of Usability on Technology Acceptance in ERP Settings

Oja, M.K. \& Lucas, W. (2011). ERP usability issues from the user and expert perspectives. Journal of Information Technology Case and Application Research, 13(3), 21-40.

Panorama Consulting Solutions. (2014). 2014 ERP Report: A Panorama Consulting Solutions Research Report" retrieved December 2014 from http://go.panorama-consulting.com/2014-ERPReport Download.html

Petter, S., Straub, D. \& Rai, A. (2006). "Specification and validation of formative constructs in IS research", working paper, Georgia State University, Atlanta, Georgia.

Preece, J., Rogers. Y. \& Sharp, H. (2011). Interaction design: Beyond human computer interaction ( $3^{\text {rd }}$ Edition). Chichester: John Wiley \& Sons Ltd.

Podsakoff, P. M., MacKenzie, S. B., Lee, J. Y., \& Podsakoff, N. P. (2003). Common method biases in behavioral research: A critical review of the literature and recommended remedies. Journal of applied psychology, 88(5), 879.

Ramayah, T. \& Lo, M.C. (2007). Impact of shared beliefs on "perceived usefulness" and "ease of use" in the Implementation of an Enterprise Resource Planning System. Management Research News, 30(6), $420-431$.

Roberts, N. \& Grover, V. (2009), "Theory development in Information Systems research using Structural Equation Modeling: Evaluation and recommendations" in Dwivedi, Y.K., Lal, B., Williams, M.D., Schneberger, S.L. \& Wade, M.R. (Eds.), Handbook of Research on Contemporary Theoretical Models in Information Systems, Hershey: IGI Global

Samander, B.A. \& Abdul Rahman, H. (2014). Job security and ERP acceptance by individuals in Saudi Arabia air transportation industry. Proceedings of the $4^{\text {th }}$ International Conference on Managemen. Kuta, Indonesia, June 16-17, 2014.

Sauro, J. (2015). SUPR-Q: A comprehensive measure of the quality of the website user experience. Journal of Usability Studies, 10(2), 68-86.

Scholtz, B., Calitz, A. \& Cilliers, C. (2013). Usability evaluation of a medium-sized ERP system in higher education. Electronic Journal of Information Systems Evaluation, 16(2), 148-161.

Seffah, A., Donyaee, M., Kline, R. B., \& Padda, H. K. (2006). Usability measurement and metrics: A consolidated model. Software Quality Journal, 14(2), 159-178.

Sekaran, U. (2006). Research methods for business: A skill building approach (4 ${ }^{\text {th }}$ Edition). Wiley India Pty Ltd.

Sharma, R., Yetton, P., \& Crawford, J. (2009). Estimating the effect of common method variance: The method - method pair technique with an illustration from TAM research. MIS Quarterly, 473-490.

Shih, Y.Y. \& Huang, S.S. (2009). The actual usage of ERP systems: An extended technology acceptance perspective. Journal of Research and Practice in Information Technology, 41(3), 263-276.

Shneiderman, B. (1996). Shneiderman's eight golden rules of interface design. Retrieved May 2015 from http://faculty.washington.edu/jtenenbg/courses/360/f04/sessions/schneidermanGoldenRules.html

Shneiderman, B., Plaisant, C., Cohen, M., Jacobs, S. Elmqvist, N. \& Diakopoulus, N. (2010). Designing the user interface: strategies for effective human-computer interaction. Pearson Education: India.

Singh, A. \& Wesson, J.L. (2009). Evaluation criteria for assessing the usability of ERP systems. Proceedings of the 2009 Annual Research Conference of the South African Institute of Computer Scientists and Information Technologists. ACM, New York, pp. 87-95.

Soto-Acosta, P., Ramayah, T. \& Popa, S. (2013). Explaining intention to use an Enterprise Resource Planning system: A replication and extension. Tehnički vjesnik, 20(3), 397-405.

Sternad, S. \& Bobek, S. (2013). Impacts of TAM-based external factors on ERP acceptance. Procedia Technology, 9, 33-42. 
Šūpulniece, I., Boguševiča, A., Petrakova, A. \& Grabis, J. (2013). Monitoring perceived usability of ERP systems in Latvian medium, small and micro enterprises. Information Technology and Management Science, 16(1), 73-78.

Surendran, K., Somarajan, C.R. \& Holsing, D. (2006). Incorporating ERP into MIS Curriculum: some insights. Information Systems Education Journal, 4(25), 3-12.

Sykes, T. A. (2015). Support structures and their impacts on employee outcomes: A longitudinal field study of an enterprise system implementation. MIS Quarterly, 39(2), 473-495.

Szajna, B. (1996). Empirical evaluation of the revised Technology Acceptance Model. Management Science, 42(1), 85-92.

Topi, H., Lucas, W.T. \& Babaian, T. (2005). Identifying usability issues with an ERP implementation. Proceedings of the $7^{\text {th }}$ International Conference on Enterprise Information Systems. 128-133.

Usmanij, P.A., Khosla, R. \& Chu, M.T. (2013). Successful product or successful system? User satisfaction measurement of ERP Software. Journal of Intelligent Manufacturing, 24(6), 1131-1144.

Vaman, J.N. (2007). ERP in practice: ERP strategies for steering organizational competence and competitive advantage. Tata McGraw-Hill, New Delhi.

Veneziano, V., Mahmud, I., Khatun, A. \& Wai-Peng, W. (2014), "Usability analysis of ERP software: Education and experience of users' as moderators", in 2014 8th International Conference on Software, Knowledge, Information Management and Applications, IEEE, pp. 1-7.

Venkatesh, V. \& Davis, F.D. (1996). A model of the antecedents of perceived ease of use: Development and test. Decision Sciences, 27(3), 451-481.

Wai-Peng, W., Veneziano, V. \& Mahmud, I. (2015). Usability of Enterprise Resource Planning software systems: an evaluative analysis of the use of SAP in the textile industry in Bangladesh, Information Development.doi: 10.1177/0266666915585364

Yeh, J.Y. (2006). Evaluating ERP performance from user perspective. Proceedings of 2006 Asia-Pacific Services Computing Conference. IEEE, Los Alamitos, CA, 311-314.

Zouine, A., \& Fenies, P. (2014). The critical success factors of the ERP system project: A meta-analysis methodology. Journal of Applied Business Research, 30(5), 1407.

\section{Biographies}

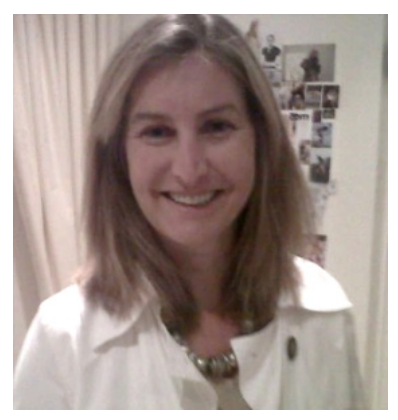

Brenda Scholtz (Ph.D.) is Head of Department for Computing Sciences at the Nelson Mandela Metropolitan University (NMMU) in Port Elizabeth. Brenda has worked in the IT industry for over 15 years as programmer, systems analyst, consultant and IT manager. She was awarded her PhD in ERP skills and education in 2012. Her research interests are in the broad field of Information Systems, more specifically related to business process management, enterprise systems, business intelligence, enterprise architectures and environmental information systems. Brenda is currently serving as project manager for several industry research collaboration programmes between South Africa and Germany. Brenda is also a member of the Institute of Information Technology Professionals South Africa (IITPSA), the Association for Information Systems (AIS) as well as the Business Architecture Guild. Brenda has published over 48 papers in international journals and conferences. 


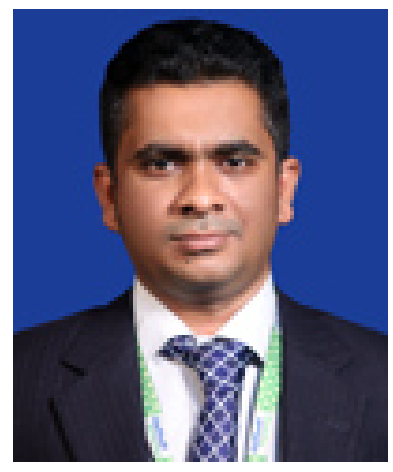

Imran Mahmud is working as an Assistant Professor at the Department of Software Engineering, Daffodil International University, Bangladesh. At the moment he is pursing PhD in Management Information System at the School of Management in Universiti Sains Malaysia. His research interests are human-computer interaction, usability testing, software engineering measurement / models and management information systems. Imran Mahmud has several research papers on enterprise resource planning (ERP) and information system published by Elsevier, Sage publications and IEEE. His full profile can be accessed from:

http://faculty.daffodilvarsity.edu.bd/profile/swe/imahmud.html

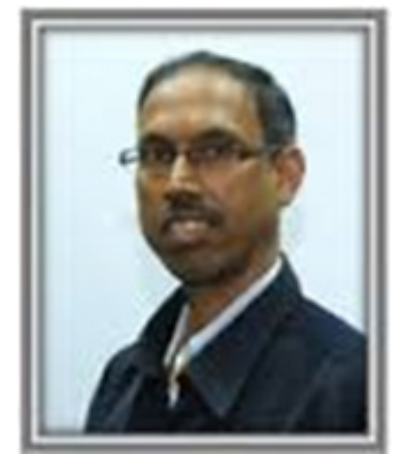

Professor T. Ramayah is currently a Professor of Technology Management at the School of Management, Universiti Sains Malaysia, Visiting Professor King Saud University, Kingdom of Saudi Arabia, Universiti Teknologi Malaysia and Adjunct Professor at Multimedia University and Universiti Tenaga Nasional, Malaysia. His publications have appeared in Information \& Management, Journal of Environmental Management, Technovation, Journal of Business Ethics, Internet Research, Journal of Travel Research, International Journal of Operations \& Production Management, Computers in Human Behavior, Resources, Conservation and Recycling, and Telematics and Informatics among others. His full profile can be accessed from

http://www.ramayah.com. 